\title{
In-Ear Energy Harvesting: Evaluation of the Power Capability of the Temporomandibular Joint
}

\author{
Jacob Bouchard-Roy, Aidin Delnavaz and Jérémie Voix
}

\begin{abstract}
Energy harvesting from human body motion is a promising source of power for future wearables and sensors. However, better knowledge on the power potentially available from each of the different types of human body motions is still required to develop efficient human-centered energy harvesting devices. This study investigates a method to evaluate the kinetic energy generated by the earcanal dynamic movements during the mastication of food. The wearable power sensing device, a hydraulic in-ear portable device, was developed for this study to measure the power associated with earcanal dynamic movements. The mean power was evaluated on six participants as they were eating. The results show that an average power of $26.2 \mathrm{~mW}$ is readily available in one earcanal from chewing an entire meal. This in-ear source of energy can ultimately be used to fully or partially power in-ear devices such as hearing aids, digital hearing protections, and emerging wearables technologies.
\end{abstract}

Index Terms-Earcanal dynamic motion, energy harvesting, power sensor, pressure transducer, temporomandibular joint.

\section{INTRODUCTION}

$\mathbf{T}$ HE human body maintains its energy in a constant state of stability by balancing the generation and consumption of energy: it absorbs the chemical energy of foods through the process of cellular respiration and stores some part of the generated energy in the body as fat or other substances. A significant part of the energy intake is used either to sustain the metabolism and maintain the body's temperature (thermal energy) or to drive the muscles to perform everyday physical activities (kinetic energy). A small amount of these thermal or kinetic energies could be sufficient to power small electronic mobile devices, thus eliminating or at least reducing their reliance on batteries.

Although numerous studies have already focused on humanpowered energy harvesting systems, knowledge regarding the properties of body-centered energy sources is still limited [1]. One of the first analyses of the types of human body energy sources was presented in [2], which describes how much power is available, on average, from body heat, respiration, blood pressure, upper limb motion and walking. Simple assumptions and basic formulas were used to evaluate the various human body energy sources. In recent years, the accuracy of these recoverable energy estimations have improved through the use of more reliable datasets, more precise measurements, and better formulations.

For example, the evaluation of the amount of thermal energy available from human daily activities could be significantly

The authors are with the Mechanical Engineering Departement at École de technologie supérieure, Montréal, QC, H3C 1K3, Canada (jeremie.voix@etsmtl.ca)

Manuscript received October 00, 2019; revised October 00, 2019. improved by using more research data on the skin temperature of additional body locations and taking into account surrounding conditions and the time of day [3]. Also, skin temperature is usually measured using thermistor probes [4], however, such measurements, which are normally found in the context of medical literature, do not account for the thermal resistance of the skin when its heat is used as a source of power. Therefore, the evaluation of the thermal energy of the body could be further improved by measuring the skin's heat flow using thermopiles [5]. Furthermore, the efficiency of thermoelectric devices is usually inferior to that of heat engines as given by Carnot's equation and as is commonly used in the literature. The thermal efficiency of the human body can be better estimated by using the thermoelectric figure of merit [6].

Improvements could also be achieved in the evaluation of the human body's kinetic energy. The amount of energy that can be harvested from body motion can be more realistically measured using the kinematics and kinetics data available in the literature for the heel strike or the ankle, knee, hip, shoulder, and elbow joint motions during walking [6]. Human body motion was initially measured by video digitizing systems and force platforms [7]. However, nowadays, accelerometers are almost exclusively used to facilitate the kinetic energy measurements of everyday activity either for the human body [8] or the human head [9]. In addition, more effective methods for collecting motion acceleration traces and more efficient algorithms to analyze these are emerging [1] to improve the estimation of the kinetic energy capacity of the human body.

Among the various human body activities, chewing has not received much attention in the literature as a source of power. However, it is the most promising activity for harvesting muscle energy in the region of the head [10]. The energy associated with chewing can be calculated by integrating the force-movement data curves generated by the biting action for different kinds of foods [11]. It is estimated that one can obtain a total bite work per day of around $580 \mathrm{~J}$ equivalent to an average power of approximately $7 \mathrm{~mW}$ [10]. In another study, a convenient flexible piezoelectric chin-strap harvested $7 \mu \mathrm{W}$ from jaw movements [12].

The chin's motion is one way to recover energy generated by chewing, but another is from the movements of the earcanal wall. During functions such as mastication, movements of the mandible result in the deformation of the earcanal, because the jaw bone (mandible) is connected to the skull (temporal bone) by a temporomandibular joint (TMJ) which is located very close to the earcanal. Kinetic power associated with these dynamic movements can be evaluated by transforming the 
resulting earcanal deformations into variations of the water level in a vertical tube and the kinetic energy thus measured is estimated to peak at $5 \mathrm{~mW}$ [13]. The peak power was then calculated for a group of 12 test-subjects based on the results obtained for their earcanal deformations using geometrical analyses of ear impressions at two jaw positions: open and closed [14]. Hence, at least $5 \mathrm{~mW}$ of maximum instantaneous power could be expected for all test-subjects performing the cycle of opening and closing their mouth.

In spite of the previously mentioned studies, the potential of the earcanal as a source of power is not yet well known. In fact, extending the test results from one to 12 testsubjects based on the analogy of their geometrical analyses of earcanal deformation does not reflect the full capacity of such subject-dependent and time-variant movements. In addition, the proposed experimental setup using a column of water to measure the earcanal energy potential is bulky. It is unsuitable for mobile applications, inadequate for outof-laboratory measurements and cannot be easily used for tests involving a large sample of subjects. While compact in-ear devices have been recently developed to measure the earcanal's dynamic activity by using piezoelectric [15] or infrared proximity sensors [16], they are unable to measure the power capability of the earcanal.

This paper presents a mobile in-ear power sensing device able to measure the power capability of the earcanal during chewing. This paper is organized as follows: Section II describes the in-ear sensor prototype and its components. The modeling of the system is developed in Section III. which also presents the required equations derived to calculate the available power from the earcanal's dynamic movements during the action of chewing. The experimental setup used on six test-subjects is presented in Section IV followed by the results and discussion in Section $\mathrm{V}$ The conclusion is drawn in Section VI

\section{IN-EAR POWER SENSING DEVICE}

The mobile in-ear power sensing device is composed of a hydraulic circuit and an electronic board. It fits within the earcanal and can measure the energy generated by the activity of the TMJ during chewing.

The device's hydraulic circuit provides a medium that can transform the earcanal's dynamic movements into a measurable value of the pressure. The circuit is illustrated in Fig. 1. It is composed of an inflatable earplug, model V5 HPD (EERS Global Technologies Inc., Montreal, QC, CA), which is normally used as a custom-fitted hearing protection device injected with a medical grade silicon, however in this study, the inflatable earpiece is installed onto a support providing two ports. It is filled with water through one of the ports using a syringe graduated with precise marks indicating the volume. A one-way valve is placed between the syringe and the earplug to prevent any backflow and to keep the fluid volume constant during the test. The other port is connected to a gauge pressure transducer ASDX015G24R (Honeywell, Charlotte, NC, USA). The pressure transducer is water compatible and capable of measuring the pressure variations generated by the dynamic movement of the earcanal. Thus, during chewing, the TMJ changes the earcanal shape (radius and curvature) resulting in the deformation of the water-filled earpiece and pressure variations inside the earplug. The operating range of the

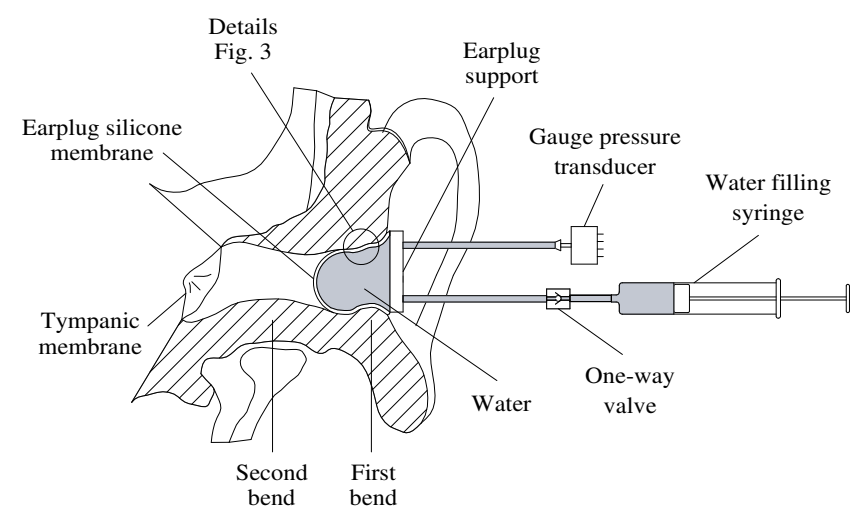

Fig. 1. Schematic of the hydraulic circuit of the in-ear power sensing device

pressure sensor was selected based on the results presented in [17] which state that $14 \mathrm{kPa}$ of pressure ensures a good fit between the earplug and the earcanal. If a leak were to happen inside the ear of the wearer, there would be no harm since the pressure is still small and the fluid is biocompatible.

The sensor package contains a Wheatstone bridge, an amplifier and all the necessary components for signal conditioning. As for data processing and storage, an Arduino Bluefruit NRF52 card (Adafruit Industries, NY, USA) was used for its integrated 12-bit analog-digital converter (ADC) and its compact size. The sampling was set to $100 \mathrm{~Hz}$, which is sufficiently greater than $1.5 \mathrm{~Hz}$, the typical frequency at which chewing occurs [18]. The ADC was connected to the data acquisition system, which is a battery-powered portable computer designed as an Auditory Research Platform (ARP) (CRITIAS, Montréal, QC, CA) [19] enabling communication with the ADC via USB and long-term data storage, as illustrated in Fig. 2

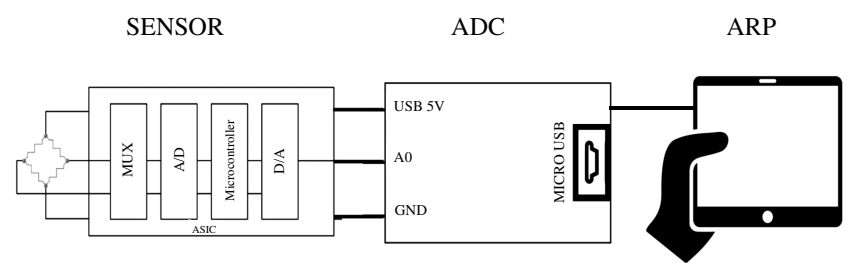

Fig. 2. Schematic of the electronic circuit of the in-ear power sensing device

The entire device is fitted into the cup of an acoustic earmuff as shown in Fig. 3 to steady the earplug inside the earcanal and ensure the easy portability of the device. The mass of the instrumented earmuff is $200 \mathrm{~g}$ with an overall size of $20 \times 15 \times 10 \mathrm{~cm}$.

\section{ENERGY MODELING OF THE POWER SENSING DEVICE}

The liquid-filled earplug can be modeled as a closed system with a volume $V$ and pressure $P$ containing the internal energy 


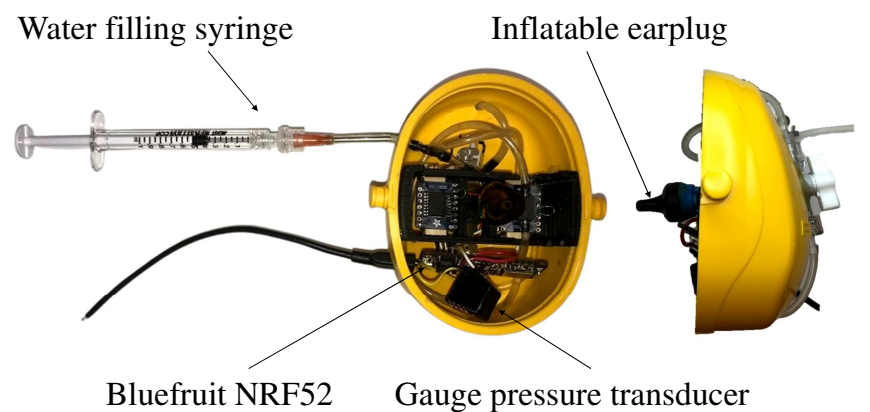

Fig. 3. Components of in-ear power sensor: inflatable earplug filled with water and an electronic circuitry fitted into the cup of an acoustic earmuff

$E_{i}$,

$$
E_{i}=P V
$$

The earplug envelope (once filled) and the earcanal wall form an elastic system whose associated energy $E_{e}$ can be written as

$$
E_{e}=\frac{1}{2} k\left(U^{2}-U_{\text {static }}^{2}\right)
$$

in which $k$ is the equivalent stiffness of the earcanal-earplug coupled system and $U$ and $U_{\text {static }}$ are the volumic deformation of the mechanical system with respect to a reference state $U_{0}$ during the dynamic movement and in the static equilibrium position respectively. The total energy $E$ of the inflated earplug fitted to the earcanal is given by adding the internal pressure and elastic deformation energy components, as written in the following energy equation:

$$
E=E_{i}+E_{e}=P V+\frac{1}{2} k\left(U^{2}-U_{\text {static }}^{2}\right)
$$

Therefore, the energy variation $\mathrm{d} E$ of the system is obtained by differentiating the energy equation as follows:

$$
\mathrm{d} E=V \mathrm{~d} P+P \mathrm{~d} V+k U \mathrm{~d} U-k U_{\text {static }} d U_{\text {static }}
$$

in which $d$ is the differential operation. If the water is assumed to be incompressible, the water volume change during the earcanal dynamic movement should be null $(\mathrm{d} V=0)$. Also, the static volume should remain constant during the test $\left(\mathrm{d} U_{\text {static }}=0\right)$ and hence

$$
\mathrm{d} E=V \mathrm{~d} P+k U \mathrm{~d} U
$$

According to (5) and by ignoring the energy loss due to dry friction, viscous damping or heat dissipation, the kinetic energy of the earcanal dynamic movement is transformed into the internal pressure increase of the water $(V \mathrm{~d} P)$ and the deformation of the earcanal-earplug system $(k U \mathrm{~d} U)$. The internal pressure energy can be easily evaluated by calculating $\mathrm{d} P$ and knowing the total volume $V$ of the injected water. However, evaluating the energy of elastic deformation is a challenge, because there is no sensor in the system capable of measuring the earplug's deformation. The deformation energy in this paper is calculated based on the experimental measurement of the equivalent stiffness, which is the extent to which the entire mechanical system resists deformations in response to a given pressure change. The total stiffness of the system can be modeled as two springs in series as shown in Fig. 4 One represents the stiffness of the earplug's membrane $k_{m}$, while the other accounts for the rigidity of the earcanal's wall $k_{e}$. The equivalent stiffness $k$ of the combined earplug

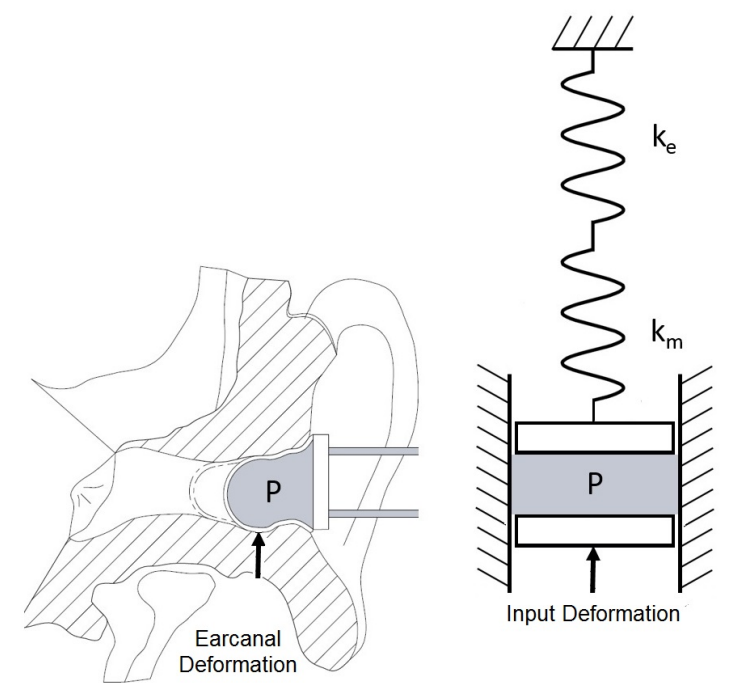

Fig. 4. Spring-mass model of the earplug's silicone membrane inside the earcanal (close-up view based on Fig. 1

and earcanal system is experimentally measured on the test subject by measuring the rate of the pressure change (measured by the pressure sensor) with respect to the volume change of the earplug (measured by the syringe with precise volume markings) as the earplug is being filled inside the subject's earcanal. Therefore, the water pressure and the earplug's volumetric deformation are related to each other by the equivalent stiffness $k$ as

$$
P=k U
$$

The derivation of 64 yields:

$$
\mathrm{d} P=k \mathrm{~d} U
$$

Substituting $U$ and $\mathrm{d} U$ from (6) and (7) into (5), yields:

$$
\mathrm{d} E=V \mathrm{~d} P+\frac{P \mathrm{~d} P}{k}
$$

The instantaneous power is consequently obtained by deriving (8) with respect to the time $t$,

$$
W=\frac{\mathrm{d} E}{\mathrm{~d} t}=\frac{V \mathrm{~d} P}{\mathrm{~d} t}+\frac{P \mathrm{~d} P}{k \mathrm{~d} t}
$$

where $W_{i}=V \mathrm{~d} P / \mathrm{d} t$ represents the power required to change the water pressure and $W_{e}=P \mathrm{~d} P / k \mathrm{~d} t$ is the power required to elastically deform the earplug and the earcanal. The total energy $E$ during the time interval $\Delta t$ is calculated by integrating (9) over the time period, as

$$
E=\int_{0}^{\Delta t} W_{i} \mathrm{~d} t+\int_{0}^{\Delta t} W_{e} \mathrm{~d} t
$$


Finally, the average power generated by the earcanal's dynamic movements during the test $W_{\text {mean }}$ is estimated by dividing the total energy from 10, by the duration of the test, $\Delta t$,

$$
W_{\text {mean }}=\frac{E}{\Delta t}
$$

\section{EXPERIMENTAL MEASUREMENTS}

Six male subjects aged 20 to 35 , having no malformation of the earcanal and being in good health participated in the test. Each test subject was asked to put on the instrumented earmuffs and attach the ARP to his belt. Then the test subject was asked to eat his lunch at a normal pace and to chew at his normal rhythm.

The human subject test procedure was approved by the École de technologie supérieure's internal review board [20]. The test subjects' right ear was verified to ensure that no wax obstructed the earcanal. The tests were performed during lunchtime, while participants ate and chewed their normal meal. The procedure of the test is as follows: First, the earpiece is inserted into the subject's earcanal and it is held in place by the instrumented earmuffs. Then, using a syringe, the hydraulic circuit is filled and flushed with water to remove any air bubbles. After this, the connections are checked for leaks.

While the earplug is being filled with water, the pressure signal is recorded at every $0.05 \mathrm{ml}$ of water injected to calculate the equivalent stiffness until it reaches $14 \mathrm{kPa}$ which is the minimum required pressure for a good fit [17]. Another criteria for the final filling pressure is the comfort of the earplug declared by the test subject during the earplug inflation. Once the fit is obtained, the filling syringe is removed and the measurements can begin. Fig. 5 shows a test subject wearing the in-ear power sensing device during the test.

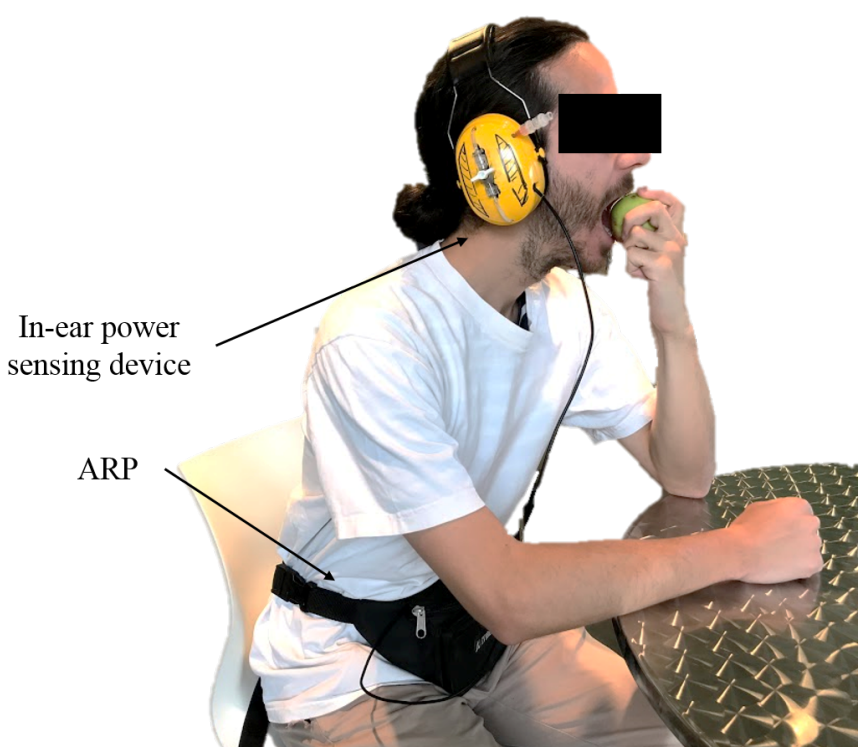

Fig. 5. In-ear power sensing device in use while data is recorded by ARP placed inside a waist pack

During the test, the pressure data is recorded in a text file using the ARP. At the end of the test, the water in the hydraulic circuit is collected, measured, and used for subsequent calculations.

\section{RESULTS AND DISCUSSION}

Fig. 6 shows the pressure variation of the system as a function of the water volume while the earplug is being filled. This graph indicates the stiffness of the system around the working pressure by using (7).

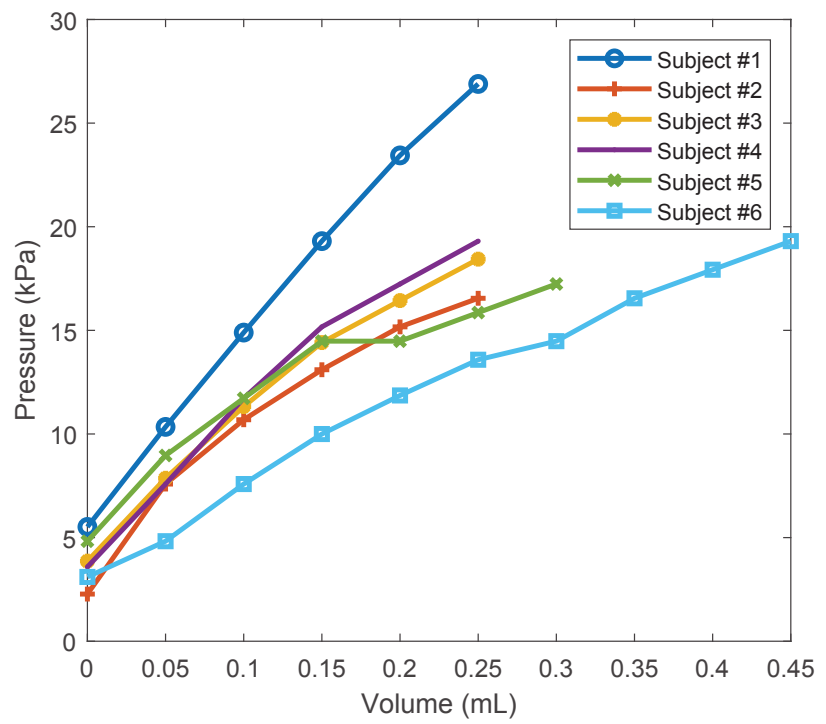

Fig. 6. Pressure-volume curves used to determine the equivalent stiffness of the earplug-earcanal system. The starting pressure differs amongst subject as the amount of prefilling water varies

The pressure variation $P$ inside the hydraulic circuit and the corresponding instantaneous power $W$ were computed for all six test subjects using (9). Fig. 7 shows a typical result of a test subject. The details of the tests and the power calculations for each test subject are listed in Table I]

A downward trend in the pressure signal can be observed in Fig. 7.a) particularly at the beginning of the test. This phenomenon can be explained by the fact that the silicone membrane is not completely impermeable to the micro-leaking of water.

The results shown in Table $\mathrm{I}$ prove that a mean chewing power of $27.8 \mathrm{~mW}$ is available inside the earcanal. The mean power has two components as depicted in 10 . The first component is the power required to increase the internal water pressure $\left(W_{i}\right)$ and the second is the power associated with the elastic deformation of the mechanical system $\left(W_{e}\right)$. While the first component represents the amount of power that can be ultimately transformed into useful energy by an actual energy harvesting device, the second power component is conserved within the mechanical elements of the system and would not be available for energy harvesting in a similar setup. Therefore, each power component is calculated separately and the results are demonstrated in Fig. 8

According to this Fig. 8 a significant part of the estimated power is associated with the internal pressure change in the 


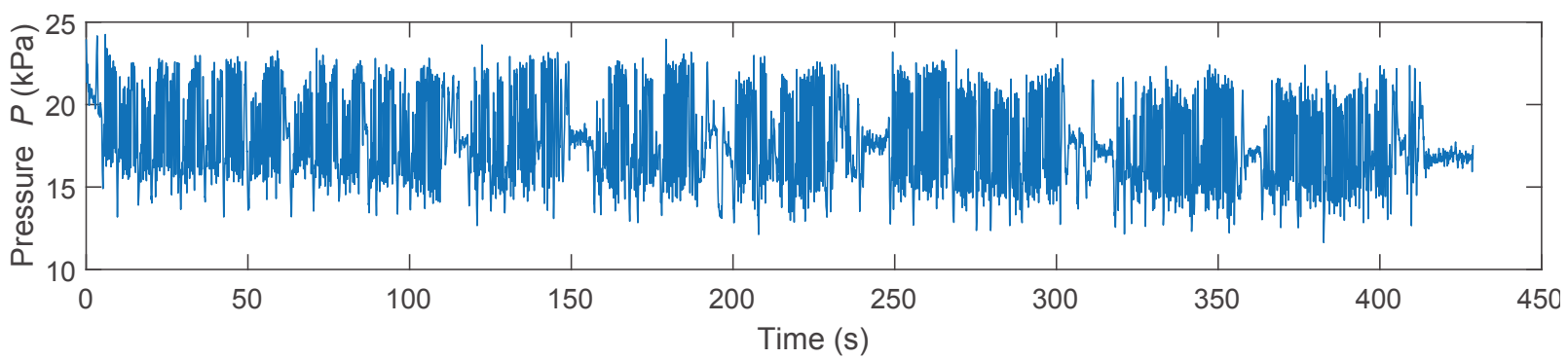

(a)

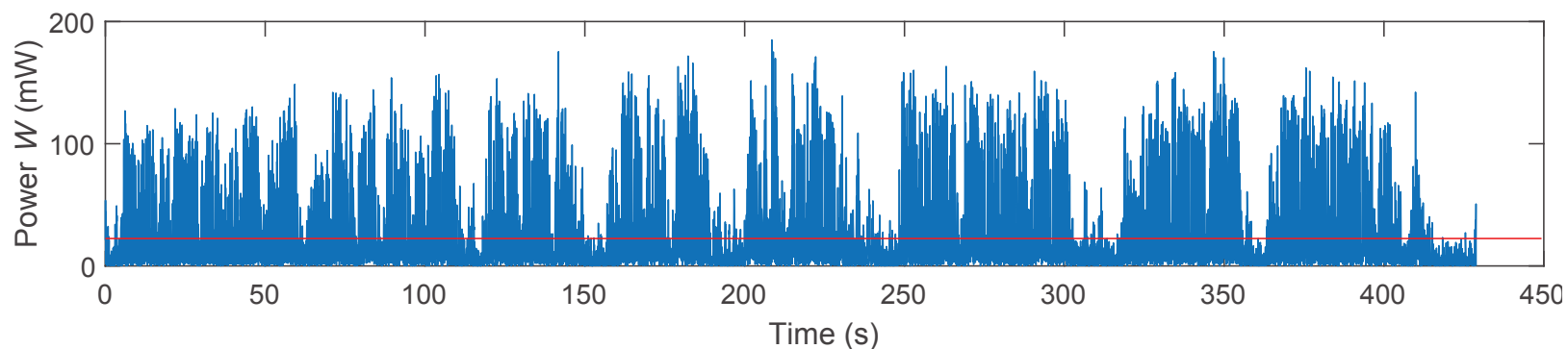

(b)

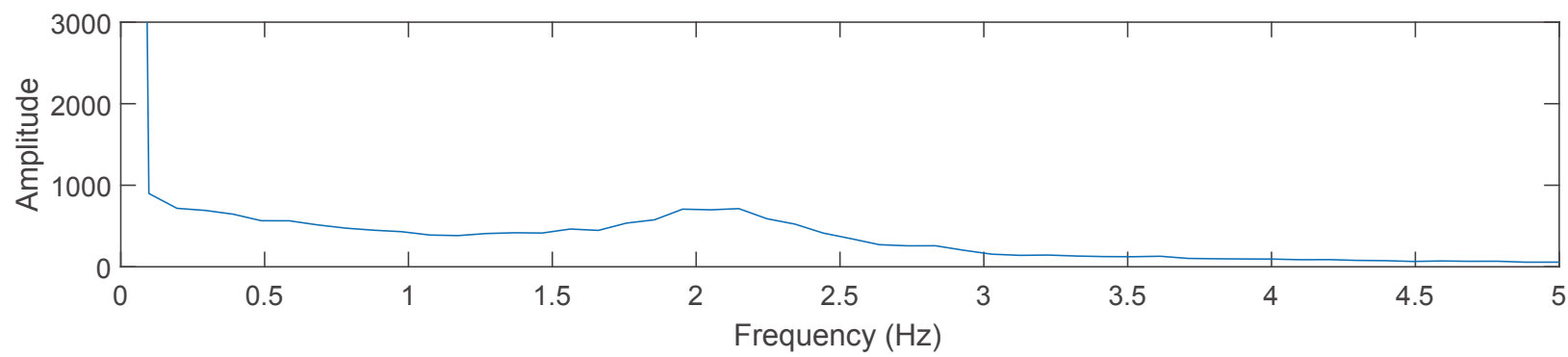

(c)

Fig. 7. Results for subject \#1 over a meal (a) pressure variation inside the earplug for subject \#1, (b) the instantaneous power and its associated average value (c) frequency spectra of chewing where the dominant frequency is around $2 \mathrm{~Hz}$

hydraulic system and hence, available for energy transformation, whereas a little portion of the total power is in the form of elastic power and is not recoverable. To quantify the available portion of the total power, the power ratio $r$ is defined as

$$
r=\frac{W_{i}}{W}=\frac{\text { Available power }}{\text { Total power }}
$$

This ratio was calculated for each test subject and the results are presented in Table II It is estimated that $91 \%$ of the total power is available, on average, if a similar deformable earpiece platform is used to harvest the energy from the earcanal dynamic movements.

The Spectral analysis of the pressure signal using the Fast Fourier Transform (FFT) reveals a dominant frequency of $1.44 \mathrm{~Hz}$ on average for the action of mastication, which is in good agreement with the chewing frequency of $1.54 \mathrm{~Hz}$ obtained in a previous research using Electromyography [18]. The individual results for the chewing frequency are also provided in Table I.

The shape of the earcanal is a complex structure characterized by two bends and variable-diameter sections [21], as illustrated in Fig 1 . The earplug used in this study does not penetrate deep inside the earcanal. It mostly occupies the space between the first and the second bends where most of the earcanal deformations occur [22]. Also, most commercial inear products do not go as deep as the second bend. Hence, it is assumed that the estimated power measured in this study is fairly representative of the achievable power from actual in-ear wearables form factors. In addition, it should be noted that the tests were only performed on one ear, the right ear of each of the test subjects to be precise, and that it is quite acceptable to assume that the total available in-ear power would double if a device to harvest power were placed in both ears, given the similarity between the movements of the right and left earcanals.

The metabolic cost of wearing such a device must be taken into account given that the earcanal movements are met with a certain amount of resistance from the water-filled earplug. This resistance is assumed to be smaller than that caused by wearing rigid earpieces, such as hearing aids or earplugs and to be still within the comfort zone of the wearer during the test. Therefore, there is a metabolic cost for wearing the inear power sensing device when compared with a non-occluded ear, but there is no extra cost when compared with an already occluded ear (e.g. someone already wearing a hearing aid or hearing protection device). 


\begin{tabular}{|c|c|c|c|c|c|c|c|c|c|c|c|}
\hline & & & & & & Partic & pants & & & & \\
\hline & Parameter & Symbol & Unit & $\# 1$ & $\# 2$ & \#3 & $\# 4$ & $\# 5$ & $\# 6$ & Average & STD \\
\hline & Circuit water volume & $V$ & $\mathrm{~mL}$ & 2.0 & 1.8 & 1.9 & 2.8 & 1.8 & 2.7 & 2.2 & 0.46 \\
\hline & Equivalent stiffness & $k$ & $\mathrm{GPa} / \mathrm{m}^{3}$ & 85.5 & 58.3 & 44.1 & 57.0 & 41.9 & 62.9 & 58.3 & 15.7 \\
\hline & Test duration & $\Delta t$ & s & 429 & 456 & 368 & 556 & 764 & 713 & 548 & 161 \\
\hline $\begin{array}{c}\text { TABLE I } \\
\text { MAIN RESULTS }\end{array}$ & Energy & $E$ & $\mathrm{~J}$ & 19.4 & 9.9 & 6.3 & 15.1 & 15.3 & 23.6 & 14.9 & 6.3 \\
\hline & Mean power & $W_{\text {mean }}$ & $\mathrm{mW}$ & 39.9 & 21.3 & 16.7 & 32.9 & 19.6 & 26.8 & 26.2 & 1.9 \\
\hline & Peak power & $W_{\text {peak }}$ & $\mathrm{mW}$ & 184.9 & 128.3 & 133.0 & 177.2 & 126.5 & 201.1 & 158.5 & 33.0 \\
\hline & Power ratio & $r$ & & $90 \%$ & $89 \%$ & $93 \%$ & $91 \%$ & $91 \%$ & $94 \%$ & $91 \%$ & $1.7 \%$ \\
\hline & Frequency & $f$ & $\mathrm{~Hz}$ & 1.95 & N/A ${ }^{1}$ & 0.68 & 0.39 & 2.15 & 2.05 & 1.44 & 0.84 \\
\hline
\end{tabular}

${ }^{1}$ No observable dominant frequency for subject \#2 (aperiodic mastication cycle)

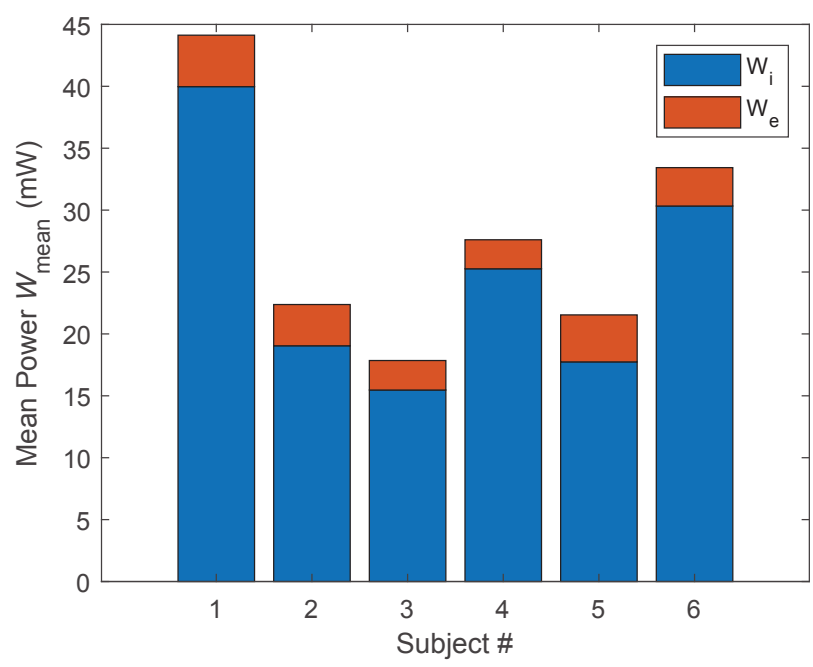

Fig. 8. Two components of the mean power available from earcanal dynamic movements for six test subjects representing the power generated by the internal pressure change $W_{i}$ and elastic deformation $W_{e}$

Finally, it should be noted that the developed prototype is intended to be used for a limited number of test subjects and during limited period of time. Some modifications would be required specially in sealing of the earplug and energy autonomy of the data acquisition system to ensure the durability and stability of the device.

\section{CONCLUSIONS}

The main goal of this work was to evaluate the power capability of the earcanal's dynamic movements when chewing. The wearable power sensor was designed, modeled and fabricated using an inflatable earplug, a pressure sensor and the required conditioning circuit, all fitted into a pair of earmuffs. The device was tested for 6 test subjects while eating the lunch. A total energy of $14.9 \mathrm{~J}$ is calculated to be generated in average during the lunch with the mean duration of $548 \mathrm{~s}$. Therefore, the average chewing power available inside a single earcanal is estimated to be around $26.2 \mathrm{~mW}$ from which $91 \%$ is stored in the water by increasing the internal pressure and the remaining is stored in the earplug membrane and the earcanal wall by elastic deformations. The estimated power is in the same order of magnitude, but relatively higher than those reported by similar studies as revealed in the first part of Table II The observed difference can be due to the more precise measuring setup, more comprehensive internal and elastic energy storage modeling and the nature of the test which is about chewing rather than simple jaw opening and closing cycles as in previous studies.

When considering the power consumption of a typical hearing aid or electronic hearing protection, which is less than $1 \mathrm{~mW}$ on average per use duration, the power generated by chewing is indeed very promising. Several attempts have already been made to tap this source of energy as demonstrated in the second part of Table II Electromagnetic induction and piezoelectric transduction have already been used for energy harvesting from the earcanal dynamic movements. However, their power output is not yet sufficient for practical applications. The results of this research can be eventually used to modify the design, improve the efficiency and help to better evaluate the performance of ear-centered energy harvesting systems.

In addition to chewing, there are other types of jaw activity such as talking, swallowing, coughing and laughing which have a great potential for in-ear energy harvesting. Therefore, further investigations of the power capability of earcanal dynamic movements should be conducted over longer periods of time during the day and should evaluate precisely, each of the different kinds of human jaw activities.

\section{ACKNOWLEDGMENTS}

The authors would like to thank EERS Global Technologies Inc. and its NSERC-EERS Industrial Research Chair in In-Ear Technologies (CRITIAS) for providing support and equipment for the experimental setups.

\section{REFERENCES}

[1] M. Gorlatova, J. Sarik, G. Grebla, M. Cong, I. Kymissis, and G. Zussman, "Movers and Shakers: Kinetic Energy Harvesting for the Internet of Things," jun 2013. [Online]. Available: http: //arxiv.org/abs/1307.0044 
TABLE II

COMPARISON OF DIFFERENT STUDIES

\begin{tabular}{|l|r|r|}
\hline & Power & Reference \\
\hline \multicolumn{2}{|l|}{ Studies on in-ear energy capability } \\
\hline Earcanal impressions & $5.0 \mathrm{~mW}$ & \\
Earcanal dynamic modeling & & \\
$\quad$-on bending & $15.0 \mathrm{~mW}$ & 24 \\
-on radial compression & $3.9 \mathrm{~mW}$ & \\
In-ear power sensor (Current study) & $26.2 \mathrm{~mW}$ & \\
\hline \multicolumn{2}{|l|}{ Studies on in-ear energy harvesting } \\
\hline Hydro-electromagnetic & $0.3 \mu \mathrm{W}$ & \\
Piezoelectric & $0.2 \mu \mathrm{W}$ & 23 \\
$\quad$-Piezo-Ring & $70.0 \mu \mathrm{W}$ & 23 \\
-Piezo-earpiece & $0.5 \mathrm{pW}$ & \\
-Earcanal bending sensor &
\end{tabular}

[2] T. Starner, "Human-powered wearable computing," IBM Systems Journal, vol. 35, no. 3, pp. 618-629, 1996. [Online]. Available: http: |/ieeexplore.ieee.org/lpdocs/epic03/wrapper.htm?arnumber=5387209

[3] M. Zhou, M. S. H. Al-Furjan, J. Zou, and W. Liu, "A review on heat and mechanical energy harvesting from human Principles, prototypes and perspectives," Renewable and Sustainable Energy Reviews, vol. 82, pp. 3582-3609, feb 2018. [Online]. Available: https://linkinghub.elsevier.com/retrieve/pii/S1364032117314776

[4] P. Webb, "Temperatures of skin, subcutaneous tissue, muscle and core in resting men in cold, comfortable and hot conditions," European Journal of Applied Physiology and Occupational Physiology, vol. 64, no. 5, pp. 471-476, 1992. [Online]. Available: http: //link.springer.com/10.1007/BF00625070

[5] V. Leonov, "Human Machine and Thermoelectric Energy Scavenging for Wearable Devices," ISRN Renewable Energy, vol. 2011, pp. 1-11, 2011. [Online]. Available: https://www.hindawi.com/archive/2011/785380/

[6] R. Riemer and A. Shapiro, "Biomechanical energy harvesting from human motion: theory, state of the art, design guidelines, and future directions," Journal of NeuroEngineering and Rehabilitation, vol. 8, no. 1, p. 22, 2011. [Online]. Available: http: //jneuroengrehab.biomedcentral.com/articles/10.1186/1743-0003-8-22

[7] D. A. Winter, A. E. Patla, J. S. Frank, and S. E. Walt, "Biomechanical Walking Pattern Changes in the Fit and Healthy Elderly," Physical Therapy, vol. 70, no. 6, pp. 340-347, jun 1990. [Online]. Available: https://academic.oup.com/ptj/article/3051935/Biomechanical

[8] T. von Buren, P. Lukowicz, and G. Troster, "Kinetic energy powered computing - an experimental feasibility study," in Seventh IEEE International Symposium on Wearable Computers, 2003. Proceedings. IEEE, pp. 22-24. [Online]. Available: http://ieeexplore.ieee.org/lpdocs/ epic03/wrapper.htm?arnumber $=1241389$

[9] J. Smilek and Z. Hadas, "A study of kinetic energy harvesting for biomedical application in the head area," Microsystem Technologies, dec 2015. [Online]. Available: http://link.springer.com/10.1007/s00542015-2766-2

[10] E. Goll, H.-P. Zenner, and E. Dalhoff, "Upper bounds for energy harvesting in the region of the human head." IEEE transactions on bio-medical engineering, vol. 58, no. 11, pp. 3097-103, nov 2011. [Online]. Available: http://www.ncbi.nlm.nih.gov/pubmed/21813361

[11] X. XU and S. YUAN, "AN EXAMINATION OF THE FORCE GENERATED FROM INCISOR PENETRATION INTO FOODS WITH DIFFERENT TEXTURAL PROPERTIES PART I: EXPERIMENTAL OBSERVATION," Journal of Texture Studies, vol. 42, no. 3, pp. 228-235, jun 2011. [Online]. Available: http://doi.wiley.com/10.1111/ j.1745-4603.2011.00295.x

[12] A. Delnavaz and J. Voix, "Flexible piezoelectric energy harvesting from jaw movements," Smart Materials and Structures, vol. 23, no. 10, p. 105020, oct 2014. [Online]. Available: http://stacks.iop.org/0964-1726/ 23/i=10/a=105020?key=crossref.7113ed90d8a66857de33072a004b7f77

[13] —, "Energy Harvesting for In-Ear Devices Using Ear Canal Dynamic Motion," IEEE Transactions on Industrial Electronics, vol. 61 , no. 1, pp. 583-590, jan 2014. [Online]. Available: http: //ieeexplore.ieee.org/lpdocs/epic03/wrapper.htm?arnumber=6420936

[14] — "Ear canal dynamic motion as a source of power for in-ear devices," Journal of Applied Physics, vol. 113, no. 6, p. 064701, 2013. [Online]. Available: http://link.aip.org/link/JAPIAU/v113/i6/p064701/ $\mathrm{s} 1\{\&\} \mathrm{Agg}=\mathrm{doi}$

[15] J. Carioli, A. Delnavaz, R. J. Zednik, and J. Voix, "Piezoelectric Earcanal Bending Sensor," IEEE Sensors Journal, vol. 18, no. 5, pp.
2060-2067, mar 2018. [Online]. Available: http://ieeexplore.ieee.org/ document/8194832/

[16] A. Bedri, D. Byrd, P. Presti, H. Sahni, Z. Gue, and T. Starner, "Stick it in your ear: Building an in-ear jaw movement sensor," in Proceedings of the 2015 ACM International Joint Conference on Pervasive and Ubiquitous Computing and Proceedings of the 2015 ACM International Symposium on Wearable Computers - UbiComp '15. New York, New York, USA: ACM Press, 2015, pp. 1333-1338. [Online]. Available: http://dl.acm.org/citation.cfm?doid=2800835.2807933

[17] M. C. Turcot and J. Voix, "United States Patent Application: 20110079227 "Pressure regulation mechanism for inflatable in-ear device"," 2011. [Online]. Available: http://appft.uspto.gov/netacgi/nph-Parser?Sect1=PTO2 $\{\&\}$ Sect2= HITOFF $\{\&\} \mathrm{p}=1\{\&\} \mathrm{u}=/$ netahtml/PTO/search-bool.html $\{\&\} \mathrm{r}=4\{\&\} \mathrm{f}=$ $\mathrm{G}\{\&\} \mathrm{l}=50\{\&\} \mathrm{col}=\mathrm{AND}\{\&\} \mathrm{d}=\mathrm{PG} 01\{\&\} \mathrm{s} 1=$ voix.IN. $\{\&\} \mathrm{OS}=$ IN/voix $\{\&\}$ RS $=$ IN/voix

[18] J. Po, J. Kieser, L. Gallo, A. Tsenyi, P. Herbison, and M. Farella, "Time-Frequency Analysis of Chewing Activity in the Natural Environment," Journal of Dental Research, vol. 90, no. 10, pp. 12061210, Oct. 2011. [Online]. Available: http://journals.sagepub.com/doi/ $10.1177 / 0022034511416669$

[19] N.-E. I. R. C. in In-Ear Technologies (CRITIAS ), "Auditory Research Platform (ARP)." [Online]. Available: http://critias.etsmtl.ca/ the-technology/arp/

[20] J. Bouchard-Roy and A. Delnavaz, "valuation du potentiel nergtique li l'activit temporo-mandibulaire au quotidien H20180606," 2018.

[21] C. Nielsen and S. Darkner, "The cartilage bone junction and its implication for deep canal hearing instrument fittings," The Hearing Journal, vol. 64 , no. 3 , pp. $35,36,40,42,2011$.

[22] R. J. Oliveira, "The Active Earcanal," Journal of american Academy of Audiology, p. 10, 1997

[23] A. Delnavaz and J. Voix, "Energy Harvesting for In-Ear Devices Using Ear Canal Dynamic Motion," IEEE Transactions on Industrial Electronics, vol. 61, no. 1, pp. 583-590, Jan. 2014.

[24] J. Carioli, A. Delnavaz, R. J. Zednik, and J. Voix, "Power capacity from earcanal dynamic motion," AIP Advances, vol. 6, no. 12, p. 125203, dec 2016. [Online]. Available: http://aip.scitation.org/doi/ $10.1063 / 1.4971215$

[25] A. Delnavaz and J. Voix, "Piezo-earpiece for micro-power generation from ear canal dynamic motion," Journal of Micromechanics and Microengineering, vol. 23 , no. 11, p. 114001, Oct. 2013. [Online]. Available: https://doi.org/10.1088\%2F0960-1317\%2F23\%2F11\%2F114001

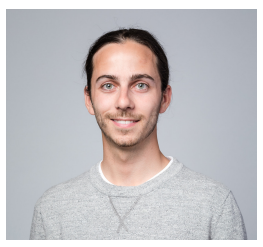

Jacob Bouchard-Roy completed his Bachelor's degree in Mechanical Engineering at École de technologie supérieure (ÉTS) in the summer of 2017, after working in the aerospace field where he gained experience in Project Management and ComputerAided Design. In the winter of 2018, he began his Master's degree in Mechanical Engineering at ÉTS with the NSERC-EERS Industrial Research Chair in In-Ear Technologies (CRITIAS). His academic experience gave him the opportunity to study at the National School of Water, Energy and Environment (ENSE3) in Grenoble, France, in the energy sector. While there, he was able to develop his skills in instrumentation and energy, his main areas of interest in engineering. 


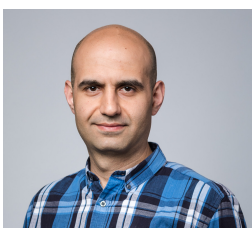

Aidin Delnavaz received his B.Sc., M.Sc. and Ph.D. degrees, all in Mechanical Engineering from Sharif University of Technology in Iran in 2002, 2004 and 2010 respectively. In 2010, he joined Sonomax-ÉTS Industrial Research Chair in In-ear Technologies where he now holds a position as an Associate Researcher. His professional (scientific) interests are in the area of vibrations, dynamics and Micro-ElectroMechanical Systems (MEMS). He is currently working on energy harvesting from the human body movement to power wearable or portable electronic

devices. Since 2014, he has also been a lecturer in the Department of Mechanical Engineering at École de technologie supérieure (ÉTS) and École polytechnique de Montréal.

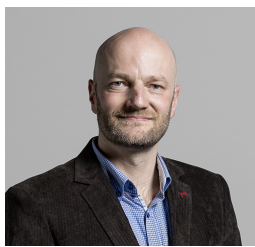

Jérémie Voix is currently an Acoustics Specialist with nearly 20 years of experience in workplace noise mitigation. Since 2000, he has been concurrently in academic and industrial settings, published his fundamental and applied research results, and continued to register patents for an advanced individual hearing protection solution. $\mathrm{He}$ is the President of the Canadian Acoustical Association, and an Associate Director (Scientific and Technological Research) at the Centre for Interdisciplinary Research in Music Media and Technology, housed at McGill Universitys Schulich School of Music, where he is also an Adjunct Professor. $\mathrm{He}$ is an Associate Member of the International Laboratory for Brain, Music, and Sound Research and a Co-Founder of the ETS-IRSST joint infrastructure laboratory for acoustic research (ICAR-Infrastructure commune en acoustique pour la recherche). He has authored or co-authored over 100 scientific publications and holds a dozen patents. As a hearing protection expert, he is regularly invited to contribute to the organization of international conferences and to review papers and theses. He was a recipient of several prizes and distinctions in recent years, including the TechnoMontréals InspirationInnovation Award in 2012, the Ordre des ingénieurs du Québec Hommage reconnaissance pour contribution exceptionnelle in 2017, and the "Early Career Award" from the International Commission for Acoustics (ICA) in 2019. Member of the Canadian Standards Association Z94.2 committee on Hearing Protection (CSA S304.3-SC), he is an active member of the American National Standard Institute (ANSI) S12 WG11 working group. He was in charge of writing the technical content of ANSI S12.71-2018 standard, which now governs field attenuation measurement systems for hearing protectors. 